\title{
A top-down approach of surface carbonyl sulfide exchange by a Mediterranean oak forest ecosystem in southern France
}

\author{
Sauveur Belviso ${ }^{1}$, Ilja Marco Reiter ${ }^{2,3}$, Benjamin Loubet ${ }^{4}$, Valérie Gros ${ }^{1}$, Juliette Lathière ${ }^{1}$, David Montagne ${ }^{4}$, \\ Marc Delmotte $^{1}$, Michel Ramonet ${ }^{1}$, Cerise Kalogridis ${ }^{1}$, Benjamin Lebegue ${ }^{1}$, Nicolas Bonnaire ${ }^{1}$, Victor Kazan ${ }^{1}$, \\ Thierry Gauquelin ${ }^{5}$, Catherine Fernandez ${ }^{5}$, and Bernard Genty ${ }^{3}$ \\ ${ }^{1}$ Laboratoire des Sciences du Climat et de l'Environnement, LSCE/IPSL, CEA-CNRS-UVSQ, Université Paris-Saclay, \\ 91191 Gif-sur-Yvette, France \\ ${ }^{2}$ CNRS, FR 3098 ECCOREV, Europôle de l'Arbois, 13545 Aix-en-Provence, France \\ ${ }^{3}$ CEA, CNRS, Aix-Marseille University, UMR 7265 Biologie Végétale et Microbiologie Environnementales, \\ 13115 Saint Paul-lez-Durance, France \\ ${ }^{4}$ AgroParisTech, INRA, Université Paris-Saclay, UMR 1402 Ecosys, 78850 Thiverval-Grignon, France \\ ${ }^{5}$ Aix Marseille Univ, Avignon Université, CNRS, IRD, IMBE Institut Méditerranéen de Biodiversité et \\ d'Ecologie marine et continentale, Marseille, France
}

Correspondence to: Sauveur Belviso (sauveur.belviso@1sce.ipsl.fr)

Received: 16 June 2016 - Published in Atmos. Chem. Phys. Discuss.: 5 July 2016

Revised: 26 October 2016 - Accepted: 13 November 2016 - Published: 2 December 2016

\begin{abstract}
The role that soil, foliage, and atmospheric dynamics have on surface carbonyl sulfide (OCS) exchange in a Mediterranean forest ecosystem in southern France (the Oak Observatory at the Observatoire de Haute Provence, O3HP) was investigated in June of 2012 and 2013 with essentially a top-down approach. Atmospheric data suggest that the site is appropriate for estimating gross primary production (GPP) directly from eddy covariance measurements of OCS fluxes, but it is less adequate for scaling net ecosystem exchange (NEE) to GPP from observations of vertical gradients of OCS relative to $\mathrm{CO}_{2}$ during the daytime. Firstly, OCS and carbon dioxide $\left(\mathrm{CO}_{2}\right)$ diurnal variations and vertical gradients show no net exchange of OCS at night when the carbon fluxes are dominated by ecosystem respiration. This contrasts with other oak woodland ecosystems of a Mediterranean climate, where nocturnal uptake of OCS by soil and/or vegetation has been observed. Since temperature, water, and organic carbon content of soil at the O3HP should favor the uptake of OCS, the lack of nocturnal net uptake would indicate that its gross consumption in soil is compensated for by emission processes that remain to be characterized. Secondly, the uptake of OCS during the photosynthetic period was characterized in two different ways. We measured ozone $\left(\mathrm{O}_{3}\right)$ deposition velocities and estimated the partitioning of $\mathrm{O}_{3}$ deposition be-
\end{abstract}

tween stomatal and non-stomatal pathways before the start of a joint survey of OCS and $\mathrm{O}_{3}$ surface concentrations. We observed an increasing trend in the relative importance of the stomatal pathway during the morning hours and synchronous steep drops of mixing ratios of OCS (amplitude in the range of 60-100 ppt) and $\mathrm{O}_{3}$ (amplitude in the range of $15-30 \mathrm{ppb}$ ) after sunrise and before the break up of the nocturnal boundary layer. The uptake of OCS by plants was also characterized from vertical profiles. However, the time window for calculation of the ecosystem relative uptake (ERU) of OCS, which is a useful tool for partitioning measured NEE, was limited in June 2012 to a few hours after midday. This was due to the disruption of the vertical distribution of OCS by entrainment of OCS rich tropospheric air in the morning and because the vertical gradient of $\mathrm{CO}_{2}$ reverses when it is still light. Moreover, polluted air masses (up to $700 \mathrm{ppt}$ of OCS) produced dramatic variation in atmospheric OCS $/ \mathrm{CO}_{2}$ ratios during the daytime in June 2013, further reducing the time window for ERU calculation. 


\section{Introduction}

Terrestrial ecosystems modulate the water balance over land and fix carbon dioxide $\left(\mathrm{CO}_{2}\right)$ from the atmosphere in the form of carbon-rich materials. Experimental and modeling studies have shown that changes in atmospheric $\mathrm{CO}_{2}$ concentration and changes in climate, induced by increasing anthropogenic emissions of greenhouse gases, impact the fixation of atmospheric $\mathrm{CO}_{2}$ by plants (gross primary production, GPP) and the release of $\mathrm{CO}_{2}$ by terrestrial ecosystems (respiration, Reco) as modulated by temperature and water availability and the effects of fertilization (e.g., Arora and Boer, 2014). Large uncertainties in the determination in GPP and Reco fluxes at the continental scale and in the magnitude of effects induced by climate and fertilization remain. Furthermore, experimental and modeling studies should help to better constrain those fluxes.

In the late 1980s, vegetation was proposed to be the missing sink in the global cycle of atmospheric carbonyl sulfide (OCS; Brown and Bell, 1986; Goldan et al., 1988) and the first evidence from field observations of the uptake of OCS near the ground was provided by Mihalopoulos et al. (1989). Today, the mechanistic link between leaf $\mathrm{CO}_{2}$ and OCS exchange is well understood (Stimler et al., 2010; Seibt et al., 2010; Wohlfahrt et al., 2012) and the scientific community has reached consensus on the potential of atmospheric OCS measurements to provide independent constraints on GPP at canopy (Blonquist et al., 2011; Asaf et al., 2013), regional (Campbell et al., 2008), and global (Montzka et al., 2007; Berry et al., 2013; Launois et al., 2015) scales. However, recent studies also demonstrated limitations to the use of OCS as a GPP proxy at canopy and ecosystem scales because (1) consumption and/or production of OCS occur in soil and litter (Van Diest and Kesselmeier, 2008; Sun et al., 2015; Ogée et al., 2016; Whelan et al., 2016 and references therein), (2) in agricultural fields and midlatitude forests OCS can also be taken up by plants at night (Maseyk et al., 2014; White et al., 2010; Commane et al., 2015), and (3) the leaf relative uptake of OCS and of $\mathrm{CO}_{2}$ (LRU), which is of central importance in the calculation of GPP from eddy covariance measurements of OCS exchange $\left(L_{\mathrm{OCS}}\right)$ following Eq. (1), exhibit daily and seasonal variations of variable amplitudes (Berkelhammer et al., 2014; Maseyk et al., 2014; Commane et al., 2015).

$\mathrm{GPP}=\frac{L_{\mathrm{OCS}}}{\mathrm{LRU}} \times \frac{\left[\mathrm{CO}_{2}\right]}{[\mathrm{OCS}]}$

The character $L$ in $L_{\mathrm{OCS}}$ stands for leaf because OCS exchange equals $L_{\mathrm{OCS}}$ when other ecosystem fluxes are negligible. To address the diel LRU variations and the role of soil and litter for canopy scale analysis, some research groups are now combining canopy flux, leaf, and soil chamber measurements in the field (L. Kooijmans personal communication, September 2016).
Equation (1) can also be used for regional scale analysis (Campbell et al., 2008). At this scale, LRU also varies as a function of plant type (i.e., C3 vs. C4 plants, Stimler et al., 2011). However, Hilton et al. (2015) demonstrated that the effect of LRU variability was less significant at regional than at canopy scale because the regional spatial uncertainty in GPP is much larger than the LRU uncertainty.

The use of leaf and soil chambers offers a means of investigating in laboratory and field conditions the ability of plants and soils to degrade ambient OCS (e.g., Stimler et al., 2010; Sun et al., 2015). Approaches that avoid manipulation of biological material, such as the eddy flux, gradient, or radon-tracer methods (e.g., Maseyk et al., 2014; Commane et al., 2015; Belviso et al., 2013), can document over short and long time spans the direction and the magnitude of surface OCS exchange at the ecosystem level. At continental or global scales, biosphere-atmosphere fluxes can be assessed from dynamic global vegetation models, and all flux components can be optimized using satellite or global network data (e.g., Berry et al., 2013; Launois et al., 2015; Kuai et al., 2015). The global network NOAA ESRL for measurements of greenhouse gases in the atmosphere has been monitoring OCS mixing ratios on a weekly basis since 2000 (Montzka et al., 2007). It is in this framework that the major role of vegetation in the global budget of OCS was again emphasized. A second network (AGAGE) exists where air samples are analyzed every $60 \mathrm{~min}$, but OCS data are not yet available for public access. Other sites have recently been instrumented for long-term monitoring of atmospheric OCS concentrations and/or fluxes. They include a mixed temperate forest in North America (Harvard forest; Commane et al., 2015), a boreal pine forest in southern Finland (Hyytiälä; A. Praplan, personal communication, 2015), and a station located on the northern coast of the Netherlands (Lutjewad; H. Chen, personal communication, 2014; Kooijmans et al., 2016). Although rural and suburban areas have also been instrumented for shorter periods (Berkelhammer et al., 2014; Belviso et al., 2013 and references therein), many biomes remain unexplored. In summer 2012 and 2013, we used the facilities of the experimental field site Oak Observatory at the Observatory of the Haute Provence (O3HP), Saint Michel l'Observatoire, France, to study the biosphere-atmosphere exchanges of three atmospheric compounds (OCS, $\mathrm{CO}_{2}$, and ozone, $\mathrm{O}_{3}$ ), which share stomatal uptake as a common pathway. O3HP is a Mediterranean forest ecosystem with low canopy height dominated by deciduous downy oak, Quercus pubescens, and Montpellier Maple, Acer monspessulanum. Often occurring in the transition of climate zones from Mediterranean to sub-Mediterranean, and thus potentially rather sensitive and responsive to climate change, $Q$. pubescens is an interesting model to monitor changes affecting the Mediterranean forest ecosystems.

Our top-down approach, similar to the approach by Blonquist et al. (2011), aims to determine the role of soil, foliage, atmospheric dynamics, and air pollution in surface 
OCS exchange at the O3HP, finding consistencies and differences with other oak woodland ecosystems characterized by a Mediterranean climate, and assessing the desirability of using OCS to partition $\mathrm{O}_{3}$ deposition between stomatal and non-stomatal pathways. Since direct LRU and OCS flux measurements were not performed during the campaigns, we used the ecosystem relative uptake (ERU) approach of Campbell et al. (2008) to provide a rough estimation of LRU variations using the following equation:

$\mathrm{LRU}=[\mathrm{ERU}] \times \frac{[\mathrm{NEE}]}{[\mathrm{GPP}]}$,

where ERU is the relative gradient of OCS $\left(\mathrm{m}^{-1}\right)$ divided by the relative gradient of $\mathrm{CO}_{2}\left(\mathrm{~m}^{-1}\right)$ and NEE is the net ecosystem exchange of $\mathrm{CO}_{2}$ from eddy covariance measurements carried out at the site.

\section{Material and methods}

\subsection{Description of the site and of air circulation}

The two campaigns took place in June of 2012 and 2013. Both were of short duration (i.e., about 2 weeks). A description of the O3HP site is available in Kalogridis et al. (2014) and Santonja et al. (2015). In short, the site $\left(43.93^{\circ} \mathrm{N}\right.$, $5.71^{\circ} \mathrm{E}$ ) is located on the premises of Observatoire de Haute Provence, about $60 \mathrm{~km}$ north of Marseille, France, at an elevation of $680 \mathrm{~m}$ above mean sea level. It is implemented in a forest area that has remained untouched since at least 1945. The climate is sub-Mediterranean with dry, warm-tohot summers.

The O3HP observatory is characterized by a highly heterogeneous karstic limestone with soil pockets developing between compact and hard limestone bedrock. The soils, which never exceed $1 \mathrm{~m}$ depth, range from shallow calcaric Leptosol to deeper calcaric Cambisols (IUSS Working Group WRB, 2014). The litter overlying the A horizons (O horizons) is $1-7 \mathrm{~cm}$ strong. The A horizons of $2-10 \mathrm{~cm}$ depth are clayey, calcareous, and show high organic carbon content (Table 1). These horizons have a strong, crumbly-to-fine subangular blocky structure likely due to high earthworm burrowing activity and numerous fine roots. The humus is an "active oligomull or dysmull type" (Brêthes et al., 1995). The A/C horizon consists of thin layers of a clayey and fine blocky soil material between limestone rocks of a decametric size. Roots are observed inside the thin soil layers.

Downy oak (Quercus pubescens) and Montpellier maple (Acer monspessulanum L.) represent 75 and $25 \%$, respectively, of the foliar biomass of the dominant tree species (Kalogridis et al., 2014). The coppice, typically constituted by multiple stems sprouting from the same rooting system, is about 70 years old. Mean tree height is $5 \mathrm{~m}$, and mean diameter at breast height is $10 \mathrm{~cm}$, ranging from 0.9 to $18.6 \mathrm{~cm}$. European smoke bush (Cotinus coggygria Scop.) and many thermophilic and xerophilic herbaceous and grass species compose the understorey vegetation (Kalogridis et al., 2014). A network of soil sensors beneath and above the canopy continuously record environmental parameters, including global radiation, air and soil temperature profiles, air and soil moisture, wind speed, and rainfall, which are made accessible through the COOPERATE database (http: //cooperate.obs-hp.fr/db).

Our understanding of the atmospheric dynamics over the O3HP sampling site does not rely solely on meteorological parameters recorded at ground level by basic weather stations. The transport and dispersion of air pollutants in the southeastern part of France was extensively investigated during the "Expérience sur Site pour Contraindre les Modèles de Pollution atmosphérique et de Transport d'Emissions" (ESCOMPTE) experiment, which took place in June-July 2001 (Cros et al., 2004; Kalthoff et al., 2005). As shown by these authors for June 2001 and in Fig. S1 in the Supplement for June of 2012, 2013, and 2015, the sea breeze is a general characteristic of the atmospheric dynamics at the site in June. It flows from the W-SW in the afternoon and carries with it the photosmog of the city of Marseille. During the night and early morning hours the wind is oriented from other directions with a strong N-NE component (Fig. S1). However, one fundamental aspect of air circulation over the area is the existence of a nocturnal jet flowing at $800-1000 \mathrm{~m}$ of altitude, also with a strong N-NE component, observed in the sodar (vertical wind profiler) measurements performed by Kalthoff et al. (2005). This is of crucial importance for the interpretation of our results.

\subsection{Air sampling and analytical methods}

\subsubsection{Momentum, energy, and $\mathrm{CO}_{2}$ and isoprene fluxes}

In June 2012, momentum, energy, and $\mathrm{CO}_{2}$ fluxes were measured at the O3HP site by the eddy covariance method using a Gill-R3-HS ultrasonic anemometer placed above the forest on a $10 \mathrm{~m}$ mast and a close-path infrared $\mathrm{CO}_{2}$ and $\mathrm{H}_{2} \mathrm{O}$ gas analyzer (IRGA, Licor 7000) placed in a truck at about $35 \mathrm{~m}$ from the base of the mast (Kalogridis et al., 2014). Air was drawn from an inlet located $\sim 20 \mathrm{~cm}$ away from the anemometer, with a $45 \mathrm{~m}$ long heated PFA Teflon tubing $\left(1 / 2^{\prime \prime} \mathrm{OD}, 3 / 8^{\prime \prime} \mathrm{ID}\right.$, heated $\sim 1^{\circ} \mathrm{C}$ above ambient air temperature) at a flow rate of $\sim 64 \mathrm{~L} \mathrm{~min}^{-1}$ in order to maintain a turbulent flow. Air was then subsampled in a tube $\left(1 / 4^{\prime \prime}\right.$ OD, $1 / 8^{\prime \prime}$ ID) to the close-path IRGA. Data were sampled at $20 \mathrm{~Hz}$. Essentially, the turbulent flux of $\mathrm{CO}_{2}$ was estimated as the covariance $\overline{w^{\prime} c^{\prime}}$ of the vertical component of the wind velocity $(w)$ and the dry mole fraction of $\mathrm{CO}_{2}(c)$, multiplied by the dry air molar volume. Here the primes denote a deviation from the mean. The friction velocity $u^{*}=-\sqrt{\overline{\overline{w^{\prime} u^{\prime}}}}$, where $u$ is the along-wind air velocity component. High-frequency loss corrections were estimated with the method of Ammann et al. (2006) and averaged $10 \%$ (median). The fluxes (NEE, 
Table 1. Soil physicochemical characteristics at O3HP.

\begin{tabular}{lrrrrrrrr}
\hline Horizon & $\begin{array}{r}\text { Depth } \\
(\mathrm{cm})\end{array}$ & $\begin{array}{r}<2 \mu \mathrm{m} \\
\left(\mathrm{g} \mathrm{kg}^{-1}\right)\end{array}$ & $\begin{array}{r}2-50 \mu \mathrm{m} \\
\left(\mathrm{g} \mathrm{kg}^{-1}\right)\end{array}$ & $\begin{array}{r}50-2000 \mu \mathrm{m} \\
\left(\mathrm{g} \mathrm{kg}^{-1}\right)\end{array}$ & $\begin{array}{r}\mathrm{TOC}^{*} \\
\left(\mathrm{~g} \mathrm{~kg}^{-1}\right)\end{array}$ & $\begin{array}{r}\mathrm{N} \\
\left(\mathrm{g} \mathrm{kg}^{-1}\right)\end{array}$ & $\begin{array}{r}\mathrm{pH} \\
\left(\mathrm{g} \mathrm{kg}^{-1}\right)\end{array}$ \\
\hline Leptosol & & & & & & & & \\
$\mathrm{A}_{1}$ & $0-5$ & 560 & 340 & 96 & 167 & 8.9 & 7.1 & 6 \\
$\mathrm{~A}_{2}$ & $5-20$ & 536 & 338 & 118 & 43.1 & 2.7 & 7.6 & 10.7 \\
$\mathrm{~A} / \mathrm{C}$ & $20-50$ & 515 & 324 & 133 & 23.3 & 1.7 & 8.0 & 27.2 \\
\hline
\end{tabular}

* Total Organic Carbon.

GPP, and Reco) were calculated using the eddy covariance method as explained in Aubinet et al. (2000) and Loubet et al. (2011). In short, GPP and Reco were estimated with the method described by Kowalski et al. (2004). Briefly, the net flux of $\mathrm{CO}_{2}$ (NEE) was modeled as the sum of the ecosystem respiration (Reco) and the GPP (or assimilation) was modeled as a hyperbolic function of the incoming solar radiation (Rs).

$\mathrm{NEE}=-\mathrm{Reco}+\frac{a 1 \times \mathrm{Rs}}{a 2+\mathrm{Rs}}=-\mathrm{Reco}+\mathrm{GPP}$

By convention here Reco and GPP are positive, and NEE is counted positive when carbon is fixed by the canopy. The parameters Reco, $a 1$, and $a 2$ were estimated by minimizing the difference between the modeled and measured $\mathrm{CO}_{2}$ flux from 16 May to 17 June 2012 using the nonlinear solver in Excel and the objective function $\ln$ (mean square error between model and measurements). The comparison was only performed for well-established turbulence $\left(u^{*}>0.1 \mathrm{~m} \mathrm{~s}^{-1}\right.$ and $\left|\frac{z}{L}\right|<0.2$, where $L$ is the Obukhov length) during dry periods without rain and during the daytime $\left(\mathrm{Rs}>5 \mathrm{~W} \mathrm{~m}^{-2}\right)$. The GPP was then calculated as GPP $=\frac{a 1 \times \mathrm{Rs}}{a 2+\mathrm{Rs}}$ for all conditions.

$Q$. pubescens is a high-isoprene emitter and studies at the O3HP have shown that it is the main volatile organic compound (VOC) released by this species at the branch (Genard-Zielinski et al., 2015) and canopy scale (Kalogridis et al., 2014). Isoprene is synthesized within the leaf through metabolic processes and its emission in the atmosphere is mainly controlled by temperature and radiation (Laothawornkitkul et al., 2009 and references therein). Although it does not share a common source and sink with OCS, it was used here as additional information to understand biological processes occurring at the $\mathrm{O} 3 \mathrm{HP}$ forest.

\subsubsection{Carbonyl sulfide (OCS)}

At the O3HP site, in June 2012, air was drawn either from an inlet located at $10 \mathrm{~m}$ height $\sim 20 \mathrm{~cm}$ away from the anemometer or from a second inlet located at $2 \mathrm{~m}$ height on the same mast with $70-80 \mathrm{~m}$ long Synflex tubing (3/8" OD) flushed permanently at a flow rate of $\sim 6 \mathrm{~L} \mathrm{~min}^{-1}$. In June 2013, air was drawn solely from an inlet located at $2 \mathrm{~m}$ height, with $20 \mathrm{~m}$ long Synflex tubing (3/8" OD). The analytical instruments were run in laboratory-like conditions (air conditioning at $25^{\circ} \mathrm{C}$ ) in a small building away from the sampling plot. How the air was analyzed for OCS was described extensively in Belviso et al. (2013). However, the mass spectrometer detector was replaced in April 2012 by a pulsed flame photometric detector (PFPD). In general, air measurements $(500 \mathrm{~mL}$ STP of air trapped cryogenically at $100 \mathrm{~mL} \mathrm{~min}^{-1}$ flow rate with an ENTECH preconcentrator) were carried out on an hourly basis. Peak integration was done using SRI's PeakSimple Chromatography Data System. Calibration was performed as in Belviso et al. (2013), but the primary standard, drawn with a gas-tight syringe, was injected in a line flushed with OCS-free helium (He was passed through an empty stainless-steel trap immersed in liquid nitrogen) connected to the preconcentrator inlet. Although the calibration gas commercialized by Air Products has a tolerance of $2.5 \%$, we found an agreement better than $0.2 \%$ between the certificate of analysis $(1.013 \mathrm{ppm}$ of OCS in helium) and our own measurements of that standard ( $1.014 \pm 0.011 \mathrm{ppm}, n=6)$ using a second calibration gas provided by U. Seibt and K. Maseyk, who purchased it from Air Liquide (0.517 ppm in nitrogen). Since the PFPD response is quadratic, the calibration equation is obtained by plotting the natural logarithm of the peak area against the natural logarithm of OCS (picolitre or $\mathrm{pL}$ ). Mixing ratios are calculated by dividing pL of OCS by volumes of air dried at $-25^{\circ} \mathrm{C}$, corrected to room temperature and pressure. Semicontinuous measurement repeatability is $1 \%(1 \mathrm{SD}$, $n=38$ consecutive hourly analyses of atmospheric air from a compressed cylinder (target gas) containing 573 ppt of OCS). Accuracy and long-term repeatability (LTR) were better than $2.5 \%$ as evaluated from periodic analyses of an atmospheric air standard prepared and calibrated by NOAA ESRL containing $448.6 \mathrm{ppt}$ of OCS.

In June 2013, air was analyzed continuously for OCS using a commercially available OCS, $\mathrm{CO}_{2}, \mathrm{H}_{2} \mathrm{O}$, and $\mathrm{CO}$ off-axis integrated cavity output spectroscopy analyzer (Los Gatos Research, Enhanced Performance Model, California, USA). In early 2013 at the O3HP, the instrument was tested for the first time in the field. We calibrated the instrument with OCS measured by the GC (over a range of atmospheric concentrations of 439 to $699 \mathrm{ppt}$ inherent to the period of interest for this study). OCS data collected with a one-half $\mathrm{Hz}$ frequency by the spectroscopy analyzer were 
subsequently reduced to $5 \mathrm{~min}$ averages that corresponded to the sampling time of the GC. The OCS signal varied by less than \pm 2 ppt (standard error) in the 5 min time window. GC and LGR data showed a linear and strong positive correlation $\left(\mathrm{OCS}_{\mathrm{GC}}=1.140 \mathrm{OCS}_{\mathrm{LGR}}+12.3 \mathrm{ppt}, R^{2}=0.95, n=\right.$ 128). Absolute readings were regularly cross-checked with a NOAA ESRL standard showing good stability throughout the campaign. OCS $_{\mathrm{LGR}}$ data were essentially used to document OCS variations in between GC measurements, and they were scaled to GC data using the relationship above.

\subsubsection{Carbon dioxide $\left(\mathrm{CO}_{2}\right)$}

At the O3HP site in June 2012, air was analyzed for $\mathrm{CO}_{2}$ from two sampling lines (10 and $2 \mathrm{~m}$ height), alternately (measurement interval duration was $30 \mathrm{~min}$ and data collected during the first $10 \mathrm{~min}$ were discarded) using a commercially available PICARRO cavity ring-down spectroscopy (CRDS) analyzer (Model G2401) placed next to the OCS gas chromatograph. In addition to $\mathrm{CO}_{2}$, this instrument analyzes $\mathrm{CH}_{4}$ and $\mathrm{CO}$ mixing ratios and applies corrections for water vapor levels. Precision and stability of the measurements performed with this instrument were investigated using the rigorous testing procedures described by Yver Kwok et al. (2015) and reported in Table 1 of that paper (see instrument G2401 with serial number CFKADS2022 and ICOS ID 108). For $\mathrm{CO}_{2}$, similar or better results in terms of continuous measurement repeatability (CMR) and LTR were obtained in the field as compared to the factory or the test laboratory (i.e., 0.027 and 0.020 ppm), respectively (Yver Kwok et al., 2015). The CRDS analyzer was calibrated in the test laboratory following ICOS standard procedures, once before shipping and right after the 1-month deployment in the field.

In June 2013, air was analyzed continuously for $\mathrm{CO}_{2}$ using the LGR Enhanced Performance instrument (see above). $\mathrm{CO}_{2}$ measurements were not reported on a calibration scale.

\subsubsection{Carbon monoxide (CO)}

At the O3HP site in June 2012, air was analyzed for CO using the PICARRO CRDS analyzer described above. Precision in terms of CMR and LTR measured in the field was not as good as in the factory or the test laboratory (i.e., 6.8 and $2.2 \mathrm{ppb}$, respectively) (Yver Kwok et al., 2015). Data were calibrated as for $\mathrm{CO}_{2}$ measurements. In June 2013, air was analyzed continuously for CO using the LGR instrument. $\mathrm{CO}$ measurements were not reported on a calibration scale. $\mathrm{CO}$ was used as a semiquantitative tracer of combustion processes (biomass or fossil fuel burning).

\subsubsection{Ozone $\left(\mathrm{O}_{3}\right), \mathrm{O}_{3}$ deposition velocity $\left(V_{\mathrm{d}} \mathrm{O}_{3}\right)$ and its partitioning}

Ozone was measured at O3HP in June 2012 with an instrument based on ultraviolet absorption (model T-400 from API-Teledyne, San Diego, USA). This instrument, calibrated with an internal ozone generator (IZS, API), is operated with a flow rate of about $700 \mathrm{~mL} \mathrm{~min}^{-1}$ and delivers data every minute. In June 2013, ozone concentrations measured at a few hundred meters from the main O3HP site were downloaded from the regional air quality network Air-Paca, France, (http://www.airpaca.org/). Ozone deposition velocity $\left(V_{\mathrm{d}} \mathrm{O}_{3}\right)$ was measured at the O3HP in June 2012 with a fast $\mathrm{O}_{3}$ chemiluminescent analyzer (ATDD, NOAA, USA). The ratio method described in Muller et al. (2010) was applied to evaluate $V_{\mathrm{d}} \mathrm{O}_{3}$. Detailed description of the methodology is given in Stella et al. (2011). The canopy conductance $\left(g_{\mathrm{c}} \mathrm{O}_{3}\right)$ and non-stomatal conductance for ozone $\left(g_{\mathrm{ns}} \mathrm{O}_{3}\right)$ were estimated following Lamaud et al. (2009) as $g_{\mathrm{c}} \mathrm{O}_{3}=V_{\mathrm{d}} \mathrm{O}_{3} /(1-$ $V_{\mathrm{d}} \mathrm{O}_{3} / V_{\max } \mathrm{O}_{3}$ ), and $g_{\mathrm{ns}} \mathrm{O}_{3}=g_{\mathrm{c}} \mathrm{O}_{3}-g_{\mathrm{s}} \mathrm{O}_{3}$, where the stomatal conductance for $\mathrm{O}_{3}\left(g_{\mathrm{s}} \mathrm{O}_{3}\right)$ is equal to $g_{\mathrm{s}} \mathrm{H}_{2} \mathrm{O} \times 0.653$, this factor being the ratio of molecular diffusivities of $\mathrm{O}_{3}$ to $\mathrm{H}_{2} \mathrm{O} . V_{\max } \mathrm{O}_{3}$ is the maximum deposition velocity for ozone, which corresponds to a perfect sink of ozone at the leaf level. This is the inverse of the sum of aerodynamic $\left(R_{\mathrm{a}}\right)$ and canopy boundary layer resistances $\left(R_{\mathrm{bl}} \mathrm{O}_{3}\right)$ as $V_{\text {max }} \mathrm{O}_{3}=1 /\left(R_{\mathrm{a}}+R_{\mathrm{bl}} \mathrm{O}_{3}\right)$, those being estimated as in Lamaud et al. (2009), taken from Bassin et al. (2004).

\subsubsection{Stomatal conductance}

Canopy stomatal conductance for water vapor $\left(g_{\mathrm{s}} \mathrm{H}_{2} \mathrm{O}\right)$ was estimated in 2012 from the latent (LE) and sensible (H) heat flux from the Penman-Monteith method for relative humidity $\leq 70 \%$. Under wet conditions the stomatal conductance was estimated following Lamaud et al. (2009) based on the proportionality between the assimilation of $\mathrm{CO}_{2}$ and the conductance.

Leaf stomatal conductance was measured in June 2013 with a porometer (AP4, Delta-T Devices, Burwell, UK). Due to the unilateral distribution of stomata (hypostomatous leaf) only the abaxial sides of the leaf were measured using the "slotted" configuration of the chamber. Five leaves were sampled per tree and cycle. Light was measured holding the sensor horizontally above the leaf.

\section{Results}

\subsection{Meteorological conditions and soil climate}

The cumulated precipitations before the campaigns were about 400 and $500 \mathrm{~mm}$ since the beginning of the year (Fig. 1a). As few precipitation events of small intensity took place during the campaigns, the volumetric soil water content (measured at $5 \mathrm{~cm}$ depth) was in a decreasing phase from 

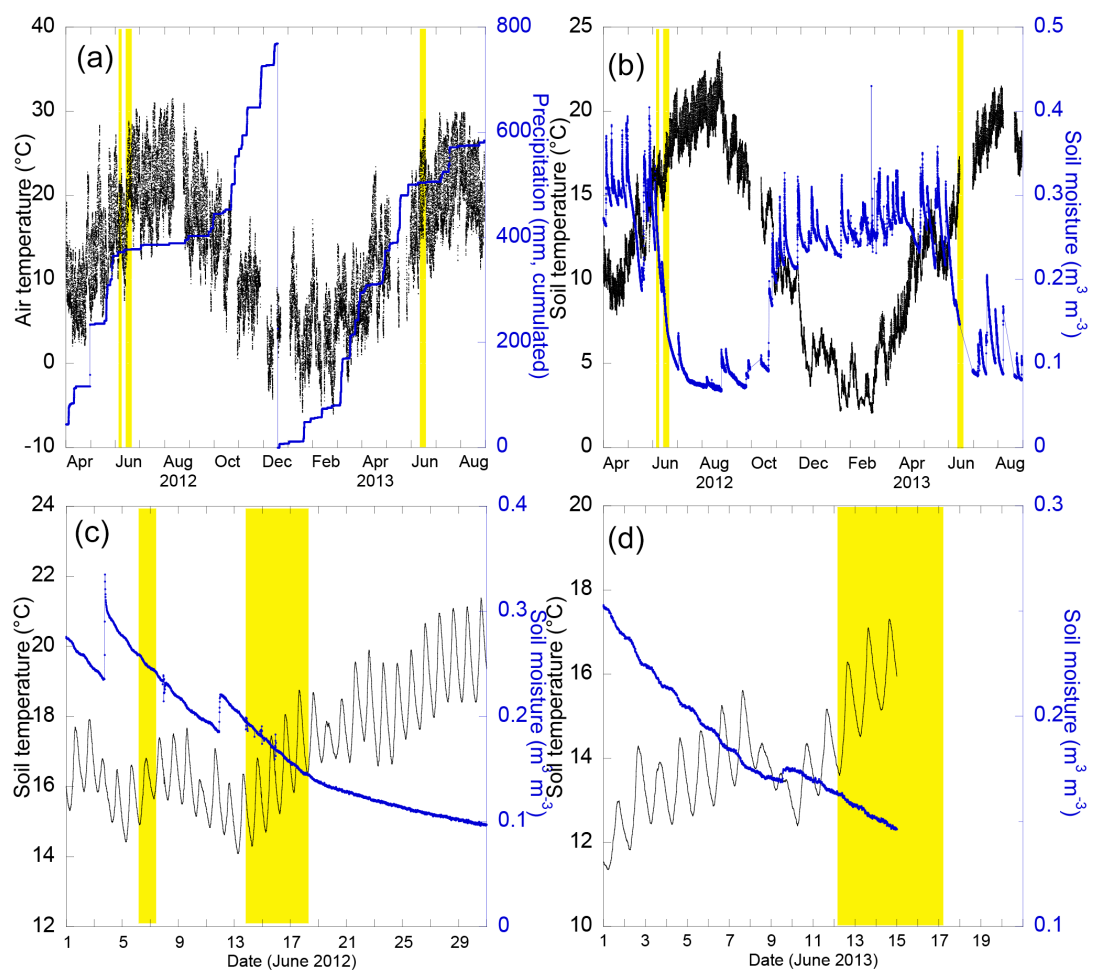

20 (d)

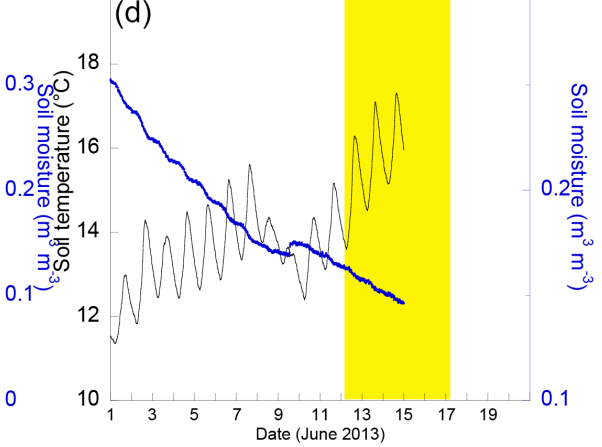

Figure 1. Monthly variations (a) in air temperature and cumulated precipitations and (b) in soil temperature and moisture ( $-10 \mathrm{~cm})$ at an oak forest ecosystem in southern France (O3HP). (c, d) Same as panel (b) but for June 2012 and June 2013. The yellow vertical bands correspond to the sampling periods.

about $0.3 \mathrm{~m}^{3} \mathrm{~m}^{-3}$ during the wet season to about $0.1 \mathrm{~m}^{3} \mathrm{~m}^{-3}$ during the dry season (Fig. 1b). Soil temperatures went the opposite way (Fig. 1b) and were in the range of 14-19 and $14-17^{\circ} \mathrm{C}$ during the 2012 and 2013 campaigns, respectively (Fig. 1c, d).

\subsection{Diel variations in the canopy $(2 \mathrm{~m})$}

In June of 2012, $\mathrm{CO}_{2}$ presented a clear and reproducible diurnal cycle with a maximum during the night (Fig. 2c). This maximum, an increase of $10-20 \mathrm{ppm}$, correlates to the decrease of global radiation (Fig. 2a). This increase occurred between the period of maximum atmospheric turbulence $\left(u^{*}>0.4 \mathrm{~m} \mathrm{~s}^{-1}\right.$, Fig. 2b), a few hours after the maximum solar radiation (Fig. 2a), and the nocturnal period when atmospheric turbulence is reduced $\left(u^{*}<0.2 \mathrm{~m} \mathrm{~s}^{-1}\right.$, Fig. 2b) and strong temperature gradients above ground level form $\left(\sim-0.5^{\circ} \mathrm{Cm}^{-1}\right.$, Fig. 2a). The temperature gradient is a proxy of low atmospheric mixing and boundary layer stability. During this period, the variability in OCS was relatively low as compared to $\mathrm{CO}_{2}$ (10 ppt at the most). The strongest temperature gradients above ground level $\left(\sim-1{ }^{\circ} \mathrm{Cm}^{-1}\right.$, Fig. 2a) were observed after sunrise (04:00 UTC), for about $2 \mathrm{~h}$. The diel cycle in the atmospheric boundary layer exhibited a much steeper decline in OCS after sunrise than at night (Fig. 2c); the same holds for ozone (Fig. 2d). The ampli- tude of the early morning drop of OCS was in the 60-100 ppt range. That of $\mathrm{O}_{3}$ was in the range of $15-30 \mathrm{ppb}$. It is worth noting that the large nocturnal maximum of $\mathrm{CO}_{2}$ was followed by a secondary one in the early morning but of shorter duration and smaller amplitude (10 ppm at the most, Fig. 2c). Hence, important variations in $\mathrm{CO}_{2}$ were observed during the period of lowest OCS concentrations. In general, OCS and $\mathrm{O}_{3}$ diel variations were in phase except in the late afternoon when we never observed a peak of OCS associated with the peaks of $\mathrm{O}_{3}$ and $\mathrm{CO}$ (Figs. $3 \mathrm{a}$ and $2 \mathrm{~d}$ ).

Figure 4 compares the mean diel patterns in ambient OCS mixing ratios at $2 \mathrm{~m}$ height in June 2012 and June 2013, constructed from data presented in Figs. $2 \mathrm{c}$ and $3 \mathrm{~b}$, respectively. Data show that the OCS concentrations were more stable at night than during the day since a drop of $\sim 50$ ppt was observed in the early morning hours, down to $\sim 450 \mathrm{ppt}$, followed by a rise up to $\sim 520 \mathrm{ppt}$ in June 2012 and $\sim 650 \mathrm{ppt}$ in June 2013. These huge diurnal variations, with amplitudes in the range of 150-250 ppt (Fig. 3b), were confirmed by independent measurements carried out with the $\mathrm{LGR} \mathrm{CO}_{2}-\mathrm{OCS}-$ $\mathrm{CO}-\mathrm{H}_{2} \mathrm{O}$ analyzer, which was running in parallel (Fig. 3b). The concomitant decrease of OCS and $\mathrm{O}_{3}$ in the early morning hours was confirmed in the 2013 records (Fig. 3b). Furthermore, the air masses richest in $\mathrm{O}_{3}$, which were transported over O3HP by strong winds in the late afternoon, were not the richest in OCS throughout the campaign (Fig. 3b). 

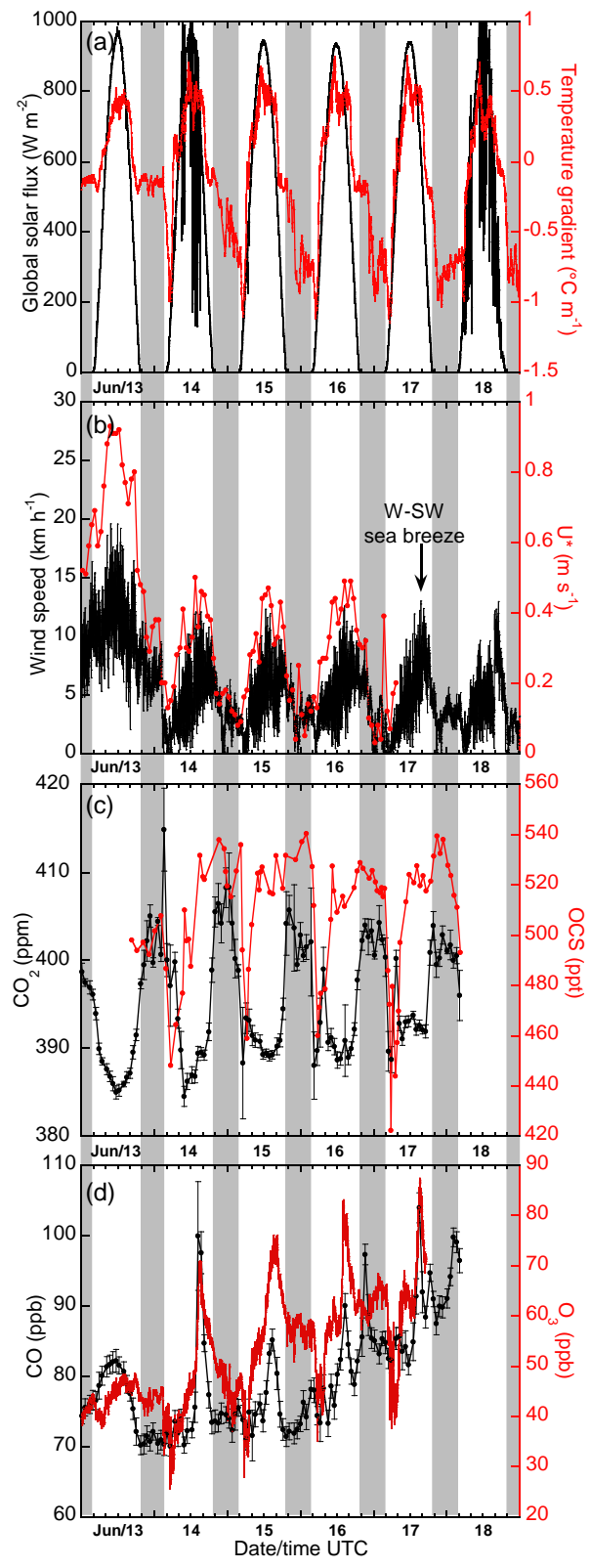

Figure 2. Time series of ambient mixing ratios of OCS, $\mathrm{CO}_{2}$, $\mathrm{CO}$, and $\mathrm{O}_{3}$ at an oak forest ecosystem in southern France $(\mathrm{O} 3 \mathrm{HP}$, June 2012 ; c, d) at $2 \mathrm{~m}$ above ground level, with incoming global radiation and thermal stratification above ground level $(\Delta T / \Delta H$ in ${ }^{\circ} \mathrm{C} \mathrm{m}^{-1}$; a) and wind speed (b). Periods of low atmospheric turbulence were evaluated using friction velocities $\left(u^{*}<0.15 \mathrm{~m} \mathrm{~s}^{-1}\right.$, b).The timescale is UTC time and the grey vertical bands correspond to nighttime.

Our ground-based meteorological and ozone observations from June 2012 and June 2013 (650 MSL), presented in Figs. 2 and 3, are highly consistent with data reported by Kalthoff et al. (2005).

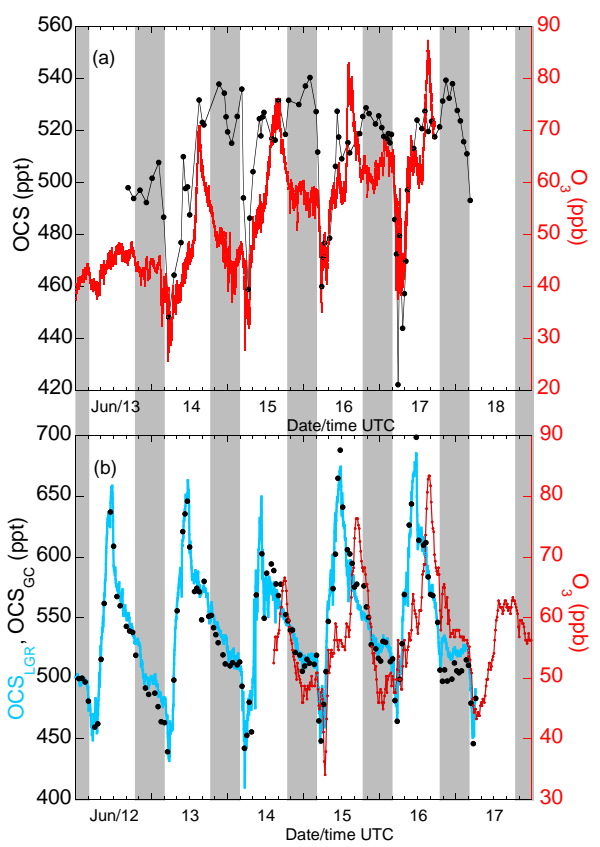

Figure 3. Diel variations in $\mathrm{OCS}$ and $\mathrm{O}_{3}$ mixing ratios at $\mathrm{O} 3 \mathrm{HP}$ in June 2012 (a) and June 2013 (b). In June 2013, two OCS analyzers were run in parallel and $\mathrm{O}_{3}$ was measured a few hundred meters from the main O3HP site. The LGR analyzer was calibrated against the $\mathrm{GC}$, OCS $_{\text {LGRcal. }}=1.14 \times \mathrm{OCS}_{\mathrm{LGRraw}}+12.3$ ppt. $\mathrm{O}_{3}$ data were downloaded from the regional air quality network Air-Paca, France (http://www.airpaca.org/).

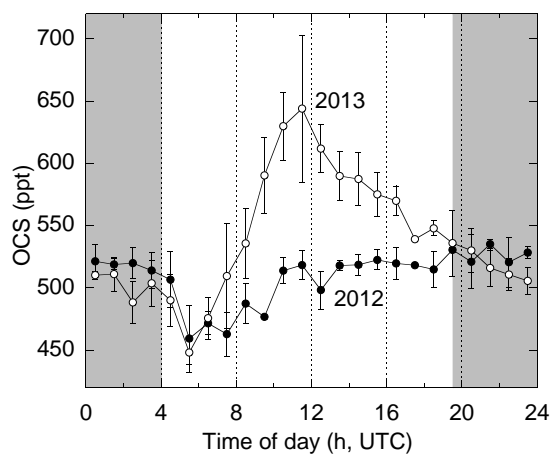

Figure 4. Mean diel patterns in ambient OCS mixing ratios at the O3HP site in June of 2012 and 2013 (displayed with dots and circles, respectively). The timescale is UTC time and the grey vertical bands correspond to nighttime. Error bars represent one standard deviation of hourly mean OCS mixing ratios recorded consecutively by the gas chromatograph for several days. Full records are displayed in Figs. 2c and 3b, respectively.

\subsection{Vertical gradients}

Diel variations in near-surface OCS and $\mathrm{CO}_{2}$ vertical gradients were documented twice in June 2012 from data collected alternatingly at 2 and $10 \mathrm{~m}$ (Fig. 5). Both time series show no apparent OCS gradient at night, whereas $\mathrm{CO}_{2}$ data showed 


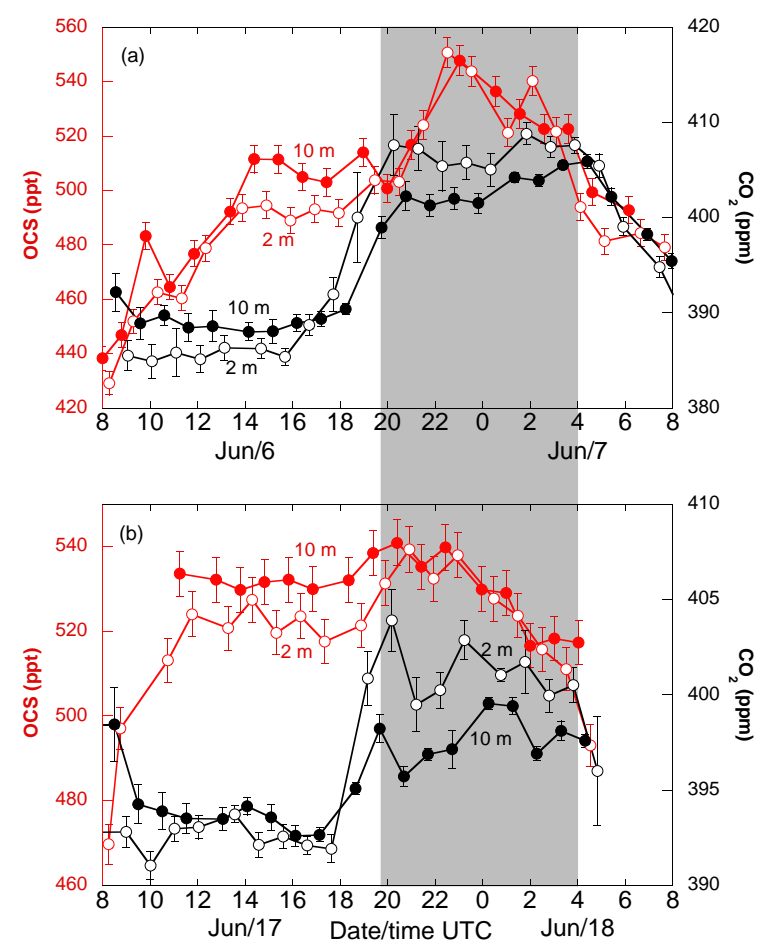

Figure 5. Time series plots showing diurnal variations in ambient OCS and $\mathrm{CO}_{2}$ mixing ratios (displayed in red and black, respectively) within and above the canopy ( 2 and $10 \mathrm{~m}$ heights, circles and dots, respectively) at the O3HP site during two measurement periods in June 2012 (a, b). The grey vertical band corresponds to nighttime. Error bars represent one standard deviation of mean $\mathrm{CO}_{2}$ mixing ratios recorded by the PICARRO instrument, which alternated measurements between 2 and $10 \mathrm{~m}$ heights on a half-hourly basis. OCS measurement repeatability is $1 \%$.

strong vertical gradients with $\mathrm{CO}_{2}$ at $2 \mathrm{~m}$ being higher by approximately $5 \mathrm{ppm}$ than at $10 \mathrm{~m}$. During the day, the $\mathrm{CO}_{2}$ gradient reversed, with $\mathrm{CO}_{2}$ mixing ratios that are lower at $2 \mathrm{~m}$ than at $10 \mathrm{~m}$ and a back-reversal of the $\mathrm{CO}_{2}$ gradient occurring in the late afternoon at 17:00-18:00 UTC. During the day, OCS mixing ratios were systematically lower at $2 \mathrm{~m}$ than at $10 \mathrm{~m}$ by a few ppt in the morning and up to $10-20 \mathrm{ppt}$ in the afternoon. Hence, $\mathrm{CO}_{2}$ and OCS were consistently lower at $2 \mathrm{~m}$ than at $10 \mathrm{~m}$ during the day. At night however, $\mathrm{CO}_{2}$ had a gradient in line with the respiratory production of $\mathrm{CO}_{2}$, whereas OCS showed no measurable gradient.

\subsection{Diel variations of fluxes and deposition velocities}

It should be noted here that the $\mathrm{CO}_{2}$ and water fluxes are not strictly linked at the ecosystem level because the non-foliar contribution is different for $\mathrm{CO}_{2}$ (non-green plant biomass, and soil respiration) and $\mathrm{H}_{2} \mathrm{O}$ (evaporation from soil and tree surfaces). Furthermore, the gas exchange between the substomatal cavity and the atmosphere has drivers that impact biological and physical processes differently (e.g., the tem- perature effect on photosynthesis and respiration for $\mathrm{CO}_{2}$ and transpiration for water). However, it is known that soil water content will impact litter decomposition processes and other microbial and rooting activity that determine soil respiration. The presence of a non-stomatal water flux is an indication of the wetness of upper soil layers; hence, it is a proxy of increased respiration rate. Negative water fluxes at dew point temperature indicate dew formation that may cause non-stomatal fluxes due to the dissolution of gases. The latent heat and $\mathrm{CO}_{2}$ fluxes (GPP and NEE) followed a clear diurnal cycle well correlated with global radiation, indicating that there was no significant water stress that would tend to lower the flux in the afternoon (Fig. 6a, b). However, the latent heat flux was significantly higher on 13 June than for later days (Fig. 6a). Higher water fluxes were also measured on 11 and 12 June, which were likely due to the evaporation of precipitation of low intensity ( $2 \mathrm{~mm}$ at the most) that occurred on 10,11, and 12 June as well as the water that was deposited as dew the nights of 11 and 12 June, which was clearly shown by the air temperature reaching the dew point temperature and the sensible heat flux being highly negative at night (data not shown). The stomatal conductance for water vapor also followed a clear diurnal cycle (Fig. S2). Significant positive isoprene fluxes were only observed during the daytime, following diel cycles with midday maxima ranging from 10 to $35 \mathrm{nmol} \mathrm{m}^{-2} \mathrm{~s}^{-1}$ (Fig. 6c redrawn from Kalogridis et al., 2014).

Unfortunately, the fast- $\mathrm{O}_{3}$ sensor that was used to assess the $\mathrm{O}_{3}$ deposition velocity had some sporadic down times that occurred frequently during the 12 to 18 June sampling period. During that period, the analyzer only performed well during one night. Good-quality data, however, were recorded continuously from 29 May to 3 June and from 7 to 9 June (Fig. 7). Stomatal conductance for $\mathrm{O}_{3}\left(g_{\mathrm{s}} \mathrm{O}_{3}\right)$ assessed with the method of Lamaud et al. (2009) followed diel cycles with midday maxima throughout the whole month of June 2012 in the range 6 to $8 \mathrm{~mm} \mathrm{~s}^{-1}$ (data not shown but Fig. 7 provides an illustration of the typical diel pattern of $g_{\mathrm{s}} \mathrm{O}_{3}$ ) for late May and the first week of June 2012. The shape of these diel cycles provides another indication that the canopy was never under water stress and the $g_{\mathrm{s}} \mathrm{O}_{3}$ is mostly light driven. The ozone deposition velocity $\left(V_{\mathrm{d}} \mathrm{O}_{3}\right)$ exhibited diurnal variations with generally larger deposition before midday (Fig. 7a). Since the stomatal conductance showed a much more symmetrical feature during daytime (Fig. 7b), it indicates that non-stomatal ozone deposition occurred preferentially during the morning. However, estimates of $g_{\text {ns }} \mathrm{O}_{3}$ were less numerous in the afternoon than in the morning because of inconsistencies between $g_{\mathrm{c}} \mathrm{O}_{3}$ and $g_{\mathrm{s}} \mathrm{O}_{3}$ values noticed during the afternoons of 29-31 May and 9 June, where $g_{\mathrm{s}} \mathrm{O}_{3}$ was higher than $g_{\mathrm{c}} \mathrm{O}_{3}$ (Fig. 7b). Nevertheless, in five cases out of six, a peak in $g_{\mathrm{ns}} \mathrm{O}_{3}$ was observed during the period between 29 May and 3 June. Data show a shift in the relative importance of both pathways since from 7 June the ozone deposition in the morning in all cases was predominantly 


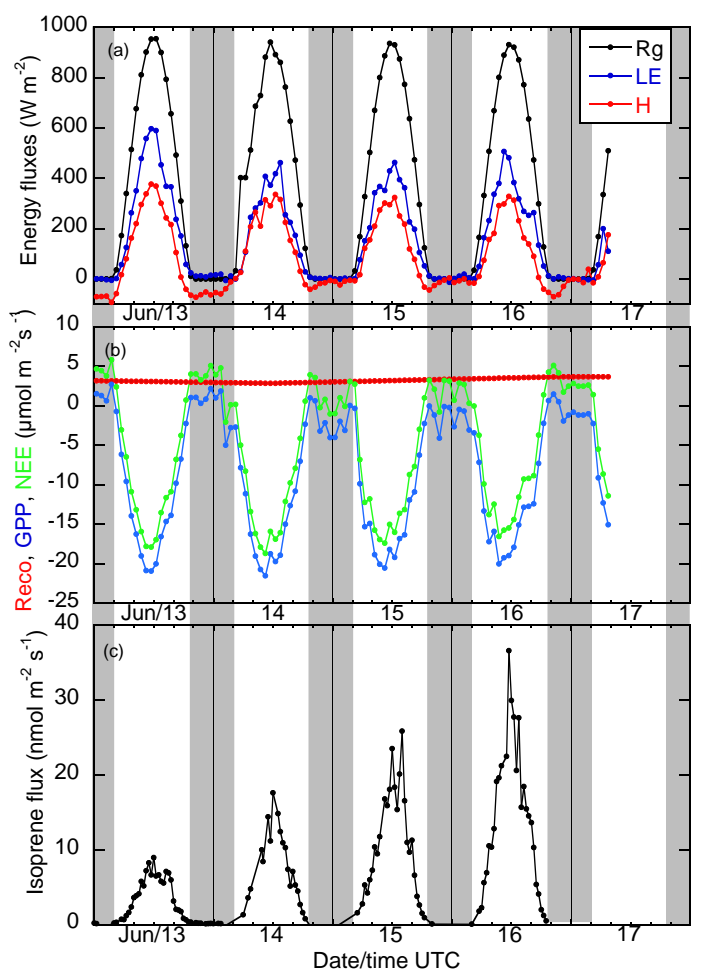

Figure 6. A 4-day time series of (a) global radiation ( $\mathrm{Rg}$ ), sensible and latent heat ( $\mathrm{H}$ and $\mathrm{LE}$ ), and of $\mathrm{CO}_{2}$ hourly fluxes from eddy covariance data measured at the O3HP site (b, June 2012). Reco, GPP, and NEE fluxes stand for ecosystem respiration, gross primary production, and net ecosystem exchange, respectively. We use the convention that negative values of fluxes indicate carbon uptake by the forest ecosystem. Panel (c) displays the isoprene fluxes measured concomitantly by the disjunct eddy covariance technique (Kalogridis et al., 2014).

through the stomatal pathway. Unfortunately, we have no indication about ozone deposition pathways during the periods where OCS was monitored in the atmosphere. However, the shift towards higher $\mathrm{O}_{3}$ deposition through the stomatal pathway during the second week of June (Fig. 7b) and the strong similarities between OCS and $\mathrm{O}_{3}$ diurnal patterns in June 2012 (Fig. 3a) suggest that the non-stomatal pathway lost importance throughout the month of June.

\section{Discussion}

\subsection{Role of atmospheric dynamics in OCS exchange}

OCS diel variations presented here (Fig. 3) resemble those reported by Berkelhammer et al. (2014) at two sites in central North America where steep rises in OCS also occurred after sunrise (see their Figs. 7b and S11). The authors suggested that this morning rise was related to boundary layer dynamics when air from above, richer in OCS than the air from the nocturnal boundary layer, was entrained downwards. This is
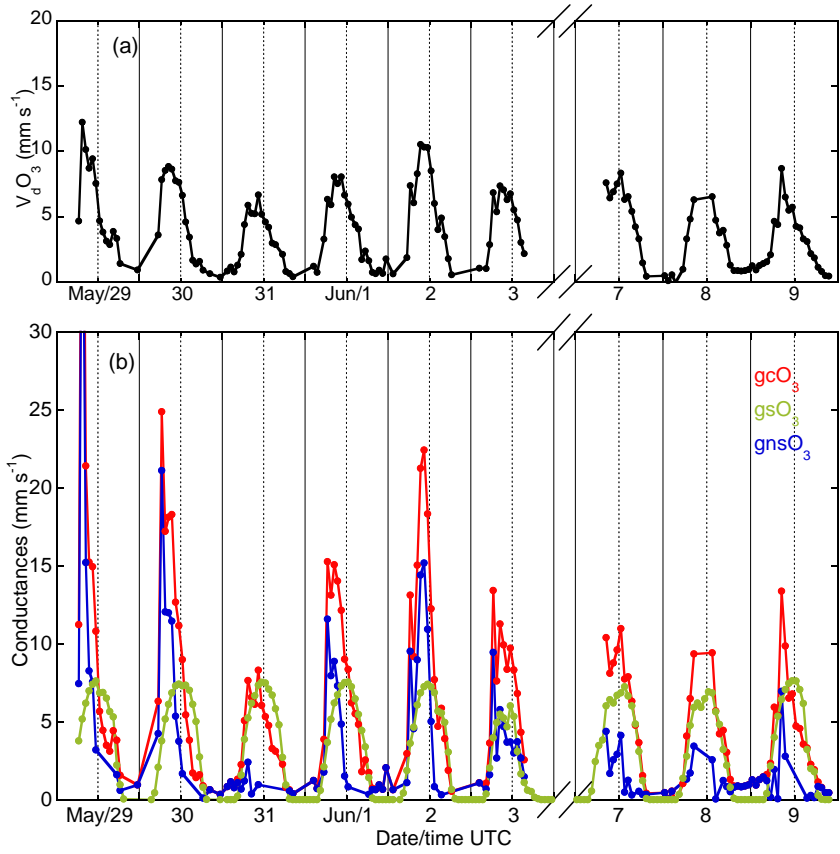

Figure 7. Diel variations in (a) ozone deposition velocity $\left(V_{\mathrm{d}} \mathrm{O}_{3}\right)$, (b) canopy conductance $\left(g_{\mathrm{c}} \mathrm{O}_{3}\right)$, stomatal conductance $\left(g_{\mathrm{s}} \mathrm{O}_{3}\right)$, and non-stomatal conductance $\left(g_{\mathrm{ns}} \mathrm{O}_{3}\right)$ from 29 May to 9 June in 2012. The partitioning was obtained with the Lamaud et al. (2009) approach (see text for details).

also the case at O3HP as shown in the vertical profiles of water vapor (Fig. S3). Entrainment of dry air from the nocturnal boundary layer is evidenced by the decrease in water vapor concentrations about $2 \mathrm{~h}$ after sunrise. This decrease is generally more important at $10 \mathrm{~m}$ than at $2 \mathrm{~m}$. However, diurnal variations with amplitudes over $200 \mathrm{ppt}$ as observed at the O3HP in June 2013 were never reported before. This raises the question of the origin of air masses rich in OCS advected over O3HP in mid-June 2013. It is highly unlikely that long-range transport of biomass burning gases and aerosols between North America and the Mediterranean region was responsible for OCS contamination because the transport of biomass burning material occurred in late June 2013 after the end of our OCS surveys (see Fig. 4 in Ancellet et al., 2016). Since the $\mathrm{O}_{3}$-rich air masses that reach the O3HP in the late afternoon lag behind those rich in OCS by $\sim 4 \mathrm{~h}$ (Fig. 3b), it is clear that the OCS and $\mathrm{O}_{3}$ peaks have distinct origins. Backward trajectories at $300 \mathrm{~m}$ above ground level ending at 12:00 UTC (Stein et al., 2015), when OCS levels at the O3HP in June 2013 were over 600 ppt (Fig. 3b), show that the circulation of the air masses during the 2012 and 2013 periods was at low altitude (below about $500 \mathrm{~m}$ a.g.l., i.e., below $1100 \mathrm{~m}$ a.s.l.); thus, they were generally in the boundary layer. The back trajectories show that the air masses were in closer contact with the continent in June 2013 than in June 2012 and that the transport in June 2013 was from the N-NW along the Rhône Valley (Fig. S4). South of the city 
of Lyon, the Rhône Valley is highly industrialized, and it is therefore likely that the O3HP site is impacted by anthropogenic direct or indirect emissions of OCS (i.e., from the oxidation of $\mathrm{CS}_{2}$ since the largest production of $\mathrm{CS}_{2}$ in western Europe is located in the Rhône Valley; Campbell et al., 2015). Polluted air very likely propagates southwards in the upper layers within the nocturnal jet, which was observed in the sodar measurements performed nearby at Cadarache (Kalthoff et al., 2005), and is entrained downwards in the morning when turbulence recovers. Moreover, we can also demonstrate that the source of OCS pollution is persistently from the same direction using data gathered in Fig. S5, which show the full June 2013 OCS record, starting from 8 June, and the corresponding back trajectories. It is clear that there is no sign of pollution in OCS when air masses, advected from the Mediterranean Sea, reach the OHP site at noon, $300 \mathrm{~m}$ a.g.l. Finally, Fig. S6 demonstrates that advection of pollutants from the combustion of fossil fuels (and from biomass burning, see above) is unlikely in the OHP area except for on the night of 15 June when CO levels went up to $250 \mathrm{ppb}$. A CO pollution event was also recorded the next morning but data show no impact on OCS levels. In the afternoon, polluted air from the metropolitan area of Marseille is transported by the sea breeze thus leading to an increase of ozone at elevated layers above the convective boundary layer as demonstrated in the air circulation study of Kalthoff et al. (2005). The highest ozone concentrations above $100 \mathrm{ppb}$ can be found about $50 \mathrm{~km}$ further downwind north and northeast of Marseille both in the mountainous areas of Luberon and above (Kalthoff et al., 2005; see Fig. 6 of that paper). We can therefore conclude that the photosmog of the city of Marseille is not a source of OCS.

\subsection{Ecosystem relative uptake (ERU)}

At the O3HP, OCS concentration gradients showing lower concentrations at $2 \mathrm{~m}$ than at $10 \mathrm{~m}$ were observed during the daytime (Fig. 5), especially during the afternoon so when turbulent mixing was strongest (Fig. 1b). Gradients were nonexistent at night. This implies that the forest ecosystem was essentially a net sink of OCS. Measured $\mathrm{CO}_{2}$ vertical gradients indicate that the forest ecosystem was a net sink of $\mathrm{CO}_{2}$ during the daytime and a net source at night, features that were confirmed by the eddy covariance data showing NEE to range between -15 and $-20 \mu \mathrm{mol} \mathrm{m}^{-2} \mathrm{~s}^{-1}$ around midday and $0-5 \mu \mathrm{mol} \mathrm{m}^{-2} \mathrm{~s}^{-1}$ at night (Fig. 6). However, the sharp rise in OCS concentrations between 06:00 and 12:00 UTC (Fig. 2) and the reversal of the $\mathrm{CO}_{2}$ gradients at 17:00-18:00 UTC (Fig. 5) reduce the time window to a few hours in the afternoon where the ecosystem relative uptake of OCS (ERU), which is the ratio of the relative vertical gradients of OCS and $\mathrm{CO}_{2}$, can be assessed. ERU is an important parameter since it is proportional to GPP and NEE scaled by the ratio of relative leaf exchange rates (LRU) following Eq. (2). Therefore, we anticipate that this approach to partition measured NEE will hardly be applicable at O3HP, not only because the amplitude of the diurnal variations in LRU is unknown at O3HP but also because vertical gradients of OCS cannot be calculated from measurements carried out throughout the whole period of illumination. In 2012, only data collected in the afternoon were exploitable and the mean OCS $/ \mathrm{CO}_{2}$ ratio at $2 \mathrm{~m}$ height was $1.33 \pm 0.02 \mathrm{ppt} \mathrm{ppm}^{-1}$, $n=27$. In June 2013, polluted air masses produced dramatic variation in atmospheric OCS $/ \mathrm{CO}_{2}$ ratios in the morning and the afternoon, leaving no time window for ERU calculation. These air masses were not related to urban photosmog episodes since there was a gap of $\sim 4 \mathrm{~h}$ between the peaks of OCS (up to $700 \mathrm{ppt}$ ) and $\mathrm{O}_{3}$ (up to $85 \mathrm{ppb}$ ). With these caveats in mind, the ratio of the mean relative vertical gradients of OCS and $\mathrm{CO}_{2}$ (calculated from linear OCS profiles) was equal to 4.7 and 4.3 for the afternoons of 6 and 17 June, respectively. However, it had a large relative error $(\geq 50 \%)$ and was consistent with ERUs reported by Blonquist et al. (2011) at the Harvard Forest AmeriFlux site in summer-autumn 2006 (5.7 \pm 1.2 (1 SD) for short-term ERU values calculated from linear OCS profiles as we did at the O3HP).

Only when the plant uptake is the dominant flux, is the ERU proportional to the ratio of GPP / NEE, with a proportionality constant that is the LRU (Campbell et al., 2008). As discussed above, this is only the case at the O3HP site for a few hours in the afternoon (because at other moments the ecosystem is not the main driver but rather part of the boundary layer dynamics) and that ERU could only be calculated using the OCS and $\mathrm{CO}_{2}$ gradients for these few hours. When ERUs and the mean NEE / GPP ratio calculated for the period 12:00-17:00 UTC $(0.78 \pm 0.05, n=20)$ are used in Eq. (2), LRUs at the O3HP are equal to 3.7 and 3.4. These values fall in the upper range of LRUs obtained from leaf chamber studies over a large range of light conditions and tree species (1-4, Stimler et al., 2010; 1.3-2.3, Berkelhammer et al., 2014).

\subsection{Relative role of plants and soil in OCS exchange}

Our OCS measurements were carried out during the period of maximum gross primary productivity of Mediterranean oak forests (Allard et al., 2008; Maselli et al., 2014). At the O3HP, the maximum of $Q$. pubescens net photosynthetic assimilation also occurs in June (Genard-Zielinski et al., 2015). The O3HP site appears to be ideal for the use of OCS uptake by plants as a tracer for GPP in a Mediterranean oak forest because the soil is neither a source nor a sink of OCS when GPP fluxes culminate. The lack of net uptake of OCS at night is a specific feature of the O3HP site that is not shared by other open oak woodlands characterized by a Mediterranean climate (Kuhn et al., 1999; Sun et al., 2015). The study of Kuhn et al. (1999) was performed in June 1994 at the Hastings Natural History Reservation in Monterey County, central coastal California (490 m a.s.l.), 
which is located in a side valley of the Carmel Valley, approximately $40 \mathrm{~km}$ from the coast. These authors reported a nocturnal drop in the OCS ambient mixing ratio by about $150 \mathrm{ppt}$ corresponding to a nocturnal OCS deposition rate of up to $-7.6 \mathrm{pmol} \mathrm{m}^{-2} \mathrm{~s}^{-1}$, which was estimated by a nocturnal boundary layer depletion model. The range of fluxes reported by Kuhn et al. (1999) is consistent with those measured using soil chambers at Stunt Ranch in southern California in April 2013 (0.1 to $-6.5 \mathrm{pmol} \mathrm{m}^{-2} \mathrm{~s}^{-1}$; Sun et al., 2015). OCS fluxes at Stunt Ranch exhibited clear diurnal variations with higher uptakes during the night than during the day (Sun et al., 2015). Unfortunately, the signature of these fluxes in the nocturnal boundary layer in terms of nocturnal drop in OCS mixing ratio was not reported in that paper. To give an illustration of what might be the atmospheric signature during stable nocturnal conditions of OCS uptake events of such intensity, we extracted data from a set of observations where the role that soil, leaf, and atmospheric dynamics have on surface OCS exchange is investigated from OCS diurnal cycles (as at O3HP) and nocturnal fluxes calculated using the radon-tracer method (Belviso et al., 2013). Figure $\mathrm{S} 7$ shows an 8-day time series of ambient mixing ratios of OCS, $\mathrm{CO}_{2}, \mathrm{CO}$, and $\mathrm{O}_{3}$ carried out in mid-April 2015 (after bud break and almost complete leaf expansion) in a suburban area of the Saclay Plateau (Paris region) in relation to incoming global radiation, thermal stratification, and wind speed (as at the O3HP). Periods of low atmospheric turbulence over the Saclay Plateau were evaluated using ${ }^{222} \mathrm{Rn}$ accumulations. In April 2015, hourly variations show nighttime and early morning decreases of OCS mixing ratios (Fig. S7c) and corresponding ${ }^{222} \mathrm{Rn}$ increases (Fig. S7b). The amplitude of OCS diurnal variations is in the $40-80$ ppt range. OCS minima coincide with calm meteorological conditions with wind velocities lower than $6 \mathrm{~km} \mathrm{~h}^{-1}$ (Fig. S7b), which are favorable to thermal stratification (Fig. S7a), with $\mathrm{CO}_{2}$ maxima sometime up to $\sim 480 \mathrm{ppm}$ (Fig. S7c) and with $\mathrm{O}_{3}$ minima down to a few ppb (Fig. S7d). However, it is worth noting here that the amplitude of $\mathrm{CO}_{2}$ and $\mathrm{O}_{3}$ nocturnal variations over the Saclay Plateau in early spring are higher than those at $\mathrm{O} 3 \mathrm{HP}$ due to anthropogenic emissions of $\mathrm{CO}_{2}$, which can be traced using $\mathrm{CO}$ mixing ratios (Fig. S7d), and to $\mathrm{NO}_{x}$ emissions, which accelerate the chemical removal of $\mathrm{O}_{3}\left(\mathrm{O}_{3}\right.$ reacts with $\mathrm{NO}$, data not shown). OCS fluxes calculated using the radon-tracer method during stable nocturnal conditions ranged from $-4.8 \mathrm{pmol} \mathrm{m}^{-2} \mathrm{~s}^{-1}$ (night of 14 April) to $-14.2 \mathrm{pmol} \mathrm{m}^{-2} \mathrm{~s}^{-1}$ (night of 11 April, Fig. S7c). They fall in the upper range of fluxes reported by Kuhn et al. (1999) and Sun et al. (2015), but the comparison should be made with caution because three different methods were used to estimate the OCS fluxes (i.e., a boundary layer model, soil chambers, and the radon-tracer method). Qualitatively, it is clear that uptake rates of several pmol $\mathrm{m}^{-2} \mathrm{~s}^{-1}$ lead to drops in the OCS ambient mixing ratio by several tens of ppt during periods of low atmospheric turbulence. Hence, a major difference between these woodlands and the O3HP site during springtime is that soil of the Mediterranean forest ecosystem of southern France is not a net sink of OCS. Soil OCS uptake has been shown to be dependent on soil physical properties like soil structure, water content, water-filled pore space, and temperature (Van Diest and Kesselmeier, 2008; Ogée et al., 2016) but also on soil biological properties like microbial activity (Kato et al., 2008; Ogawa et al., 2013), active root density (Maseyk et al., 2014), or the presence of a litter layer (Berkelhammer et al., 2014; Sun et al., 2015). Away from a range of optimum uptake, which varies between soils, changes in soil water content and temperature can markedly reduce OCS uptake by soils (Van Diest and Kesselmeier, 2008). However, the soil temperature and water content at the O3HP (Fig. 1c, d) are typically in the range of optimum uptake published by Van Diest and Kesselmeier (2008). A limitation of OCS uptake by soils due to a poor OCS diffusion is also unlikely considering that the soils from the O3HP are strongly structured and are far from being water saturated. Finally, the only physical property of soil differing among the three open oak woodlands is the soil texture, with a fine clayey texture at the O3HP but a coarse sandy loam texture at Hastings Reservation (Kuhn et al., 1999) and at stunt Ranch (Sun et al., 2015). OCS uptake by fine-textured soils has already been reported (Maseyk et al., 2014), this result pointed out the need for measurements of OCS uptake for a greater diversity of soils. Concerning the biological soil properties, the soil at the O3HP is covered by a relatively thick litter layer that may induce a change from OCS uptake to OCS emission (Berkelhammer et al., 2014). However, at Stunt Ranch Sun et al. (2015) measured that the litter was responsible for OCS uptake. The surface horizons at the O3HP showed organic carbon content ranging from 167 to $43 \mathrm{~g} \mathrm{~kg}^{-1}$ in the surface soil horizons (Table 1) but only $24 \mathrm{~g} \mathrm{~kg}^{-1}$ at Hastings Reservation (no data on soil organic carbon are available for Stunt Ranch). Being richer in organic carbon, soils at the O3HP show very likely higher microbial activity, a factor that should stimulate uptake of OCS by soils but apparently does not. If the capacity of soils to consume OCS is more related to specific enzymatic activities (carbonic anhydrase (CA) and OCS hydrolase) than to the general variables presented above, our observations would highlight deficiencies in these enzymatic activities in the calciumcarbonate-rich soils of O3HP. However, this hypothesis is not consistent with the suggestion that CA performs an essential role in microbial organisms surviving periods of osmotic stress such as drought at the surface of Mediterranean soils (Wingate et al., 2008). Finally, as roots and associated rhizosphere have been found to produce OCS, a greater abundance of roots in the surface soils at O3HP by comparison with the two other oak woodlands may explain why the soils at O3HP are not a sink of OCS. In other words, the lack of nocturnal net uptake of OCS would indicate that gross consumption of this gas in soil is compensated for by emission processes that remain to be characterized. However, no data on root abun- 
dance are available at Hastings Reservation or Stunt Ranch to confirm such a hypothesis.

\subsection{Potential use of OCS to partition ozone decay near the ground}

Data show strong similarities during the night and early morning hours between OCS and $\mathrm{O}_{3}$ diel variations at the O3HP suggesting a similar sink during that period (Fig. 3). At the O3HP, volatile organic compounds (VOCs) produced by the vegetation are essentially in the form of isoprene (Kalogridis et al., 2014; Genard-Zielinski et al., 2015). Isoprene is oxidized in the atmosphere by the hydroxyl radical $(\mathrm{OH}), \mathrm{O}_{3}$, and the nitrate radical $\left(\mathrm{NO}_{3}\right)$, but in-canopy chemical oxidation of isoprene at the O3HP was found to be weak and did not seem to have a significant impact on isoprene concentrations and fluxes above the canopy (Kalogridis et al., 2014). Hence, ozone deposition at the O3HP was essentially through leaf uptake via stomata and surface deposition, without a strong contribution from chemical reactions. In late May and early June 2012, the non-stomatal contribution to the ozone flux was in general markedly higher than the stomatal one in the morning hours (before 10:00 UTC), but it became much less significant in the afternoon (Fig. 7b). Conversely, during the second week of June, although there were still signs of non-stomatal loss of ozone in the morning, the major contribution to ozone deposition was through the stomatal pathway (Fig. 7b). The analogy with OCS at nighttime and in the early morning suggests that soil did not contribute much to the $\mathrm{O}_{3}$ flux and that the deposition flux of $\mathrm{O}_{3}$ in mid-June was essentially the result of leaf uptake. However, it is difficult to evaluate the soil ozone pathways without turbulence measurements inside the canopy. It would be worth looking further into how OCS could be used to partition ozone fluxes near the ground between soil and leaf deposition processes. The applicability of OCS to characterize the strength of ozone sinks would be reduced in situations where $\mathrm{NO}_{x}$ would significantly impact the chemical production or destruction of ozone in the canopy or when background air is contaminated by primary or secondary anthropogenic sources of OCS (Fig. 3b).

\section{Conclusions and perspectives}

Diel changes in the OCS mixing ratio and in its vertical distribution show that net soil exchange of OCS is negligible compared to the uptake of the gas through the stomata, a feature that is not shared by other oak woodland ecosystems characterized by a Mediterranean climate. Hence, O3HP would be the adequate place to support the installation of a monitoring station of OCS uptake by plants from eddy covariance measurements in the Mediterranean region. However, the assessment of GPP from measured OCS fluxes at the ecosystem scale remains a tributary of our poor knowledge of LRU diel variations at the O3HP, which requires further examination using new experimental facilities (branch chambers or bags and/or coupled NEE-ERU measurements). In the framework of the European infrastructure Integrated Carbon Observation System (ICOS), an atmospheric measurement station (100 m high tower) was set up at OHP in 2014 to determine multiyear records of greenhouse gases. Future research on the ERU is encouraged by the site being suitable to perform continuous and high-precision vertical profiles of OCS using quantum cascade laser spectrometry. Unfortunately, our preliminary surveys suggest that the site is less adequate for scaling NEE to GPP from observations of vertical gradients of OCS relative to $\mathrm{CO}_{2}$ during the daytime than for estimating GPP directly from eddy covariance measurements; the time window for calculation of the ecosystem relative uptake of OCS was found to be restricted to a few hours after midday at the O3HP (1) because in the morning the vertical distribution of OCS is disrupted by entrainment of OCS-rich tropospheric air sometimes contaminated by anthropogenic emissions and (2) because the $\mathrm{CO}_{2}$ vertical gradient reverses when it is still light.

\section{Data availability}

The data have been deposited in the CNRS Archives as a zip file and can be downloaded from: https: //mycore.core-cloud.net/public.php?service $=$ files $\& \mathrm{t}=$ 04c569376fa8ca82e5ebdf09cd18630d (Belviso et al., 2016).

\section{The Supplement related to this article is available online at doi:10.5194/acp-16-14909-2016-supplement.}

Acknowledgements. We are grateful for the support of the administrative and technical staff of the "Observatoire de Haute-Provence" and the "Institut Mediterranéen de Biodiversité et Ecologie terrestre et marine" and support from the OHP infrastructure. We are also grateful to Eric Lamaud and Jean-Marc Bonnefond from INRA for lending the NOAA ozone analyzer and the $\mathrm{Li} 7500 \mathrm{CO} 2 / \mathrm{H} 2 \mathrm{O}$ IRGA. The authors express their thanks to the staff of the SIRTA observatory, which provided access to meteorological data. The authors gratefully acknowledge the NOAA Air Resources Laboratory (ARL) for the provision of the HYSPLIT transport and dispersion model and/or READY website (http://www.ready.noaa.gov) used in this publication. This work was supported by the French National Agency for Research (ANR 2010 JCJC 60301 CANOPÉE). We also thank the EU FP7 ECLAIRE project for funding. The purchase of the LGR OCS, $\mathrm{CO}_{2}, \mathrm{H}_{2} \mathrm{O}$, and $\mathrm{CO}$ analyzer used during the 2013 field campaign was co-funded by PACA region, GIS IBiSA, CEA, CNRS, and FR 3098 ECCOREV (IMAPLANT project to B.G.).

Edited by: M. Kanakidou

Reviewed by: three anonymous referees 


\section{References}

Allard, V., Ourcival, J. M., Rambal, S., Joffre, R., and Rocheteau, A.: Seasonal and annual variation of carbon exchange in an evergreen Mediterranean forest in southern France, Glob. Change Biol., 14, 714-725, doi:10.1111/j.13652486.2008.01539.x, 2008.

Ammann, C., Brunner, A., Spirig, C., and Neftel, A.: Technical note: Water vapour concentration and flux measurements with PTR-MS, Atmos. Chem. Phys., 6, 4643-4651, doi:10.5194/acp6-4643-2006, 2006.

Ancellet, G., Pelon, J., Totems, J., Chazette, P., Bazureau, A., Sicard, M., Di Iorio, T., Dulac, F., and Mallet, M.: Long-range transport and mixing of aerosol sources during the 2013 North American biomass burning episode: analysis of multiple lidar observations in the western Mediterranean basin, Atmos. Chem. Phys., 16, 4725-4742, doi:10.5194/acp-16-4725-2016, 2016.

Arora, V. K. and Boer, G. J.: Terrestrial ecosystems response to future changes in climate and atmospheric $\mathrm{CO}_{2}$ concentration, Biogeosciences, 11, 4157-4171, doi:10.5194/bg-11-4157-2014, 2014

Asaf, D., Rotenberg, E., Tatarinov, F., Dicken, U., Montzka, S. A., and Yakir, D.: Ecosystem photosynthesis inferred from measurements of carbonyl sulphide flux, Nat. Geosci. 6, 186-190, doi:10.1038/NGEO1730, 2013.

Aubinet, M., Grelle, A., Ibrom, A., Rannik, U., Moncrieff, J., Foken, T., Kowalski, A. S., Martin, P. H., Berbigier, P., Bernhofer, C., Clement, R., Elbers, J., Granier, A., Grunwald, T., Morgenstern, K., Pilegaard, K., Rebmann, C., Snijders, W., Valentini, R., and Vesala, T.: Estimates of the annual net carbon and water exchange of forests: The EUROFLUX methodology, Adv. Ecol. Res., 30, 113-175, 2000.

Bassin, S., Calanca, P., Weidinger, T., Gerosa, G., and Fuhrer, E.: Modeling seasonal ozone fluxes to grassland and wheat: model improvement, testing, and application, Atmos. Environ., 38, 2349-2359, doi:10.1016/j.atmosenv.2003.11.044, 2004.

Belviso, S., Schmidt, M., Yver, C., Ramonet, M., Gros, V., and Launois, T.: Strong similarities between nighttime deposition velocities of carbonyl sulphide and molecular hydrogen inferred from semi-continuous atmospheric observations in Gif-sur-Yvette, Paris region, Tellus B, 65, 20719, doi:10.3402/tellusb.v65i0.20719, 2013.

Belviso, S., Gros, V., Delmotte M., Reiter, I. M., Genty, B., and Loubet, B.: DATA_Belviso_ACP_2016, available at: https://mycore.core-cloud.net/public.php?service=files\&t= 04c569376fa8ca82e5ebdf09cd18630d, last access: 30 November 2016.

Berkelhammer, M., Asaf, D., Still, C., Montzka, S., Noone, D., Gupta, M., and Yakir, D.: Constraining surface carbon fluxes using in situ measurements of carbonyl sulfide and carbon dioxide, Global Biogeochem. Cy., 28, 161-179, 2014.

Berry, J., Wolf, A., Campbell, J. E., Baker, I., Blake, N., Blake, D., and Zhu, Z.: A coupled model of the global cycles of carbonyl sulfide and $\mathrm{CO}_{2}$ : A possible new window on the carbon cycle, $\mathrm{J}$. Geophys. Res.-Biogeo., 118, 842-852, doi:10.1002/jgrg.20068, 2013

Blonquist Jr., J. M., Montzka, S. A., Munger, J. W., Yakir, D., Desai, A. R., Dragoni, D., Griffis, T. J., Monson, R. K., Scott, R. L., and Bowling, D. R.: The potential of carbonyl sulfide as a proxy for gross primary production at flux tower sites, J. Geophys. Res., 116, G04019, doi:10.1029/2011JG001723, 2011.

Brêthes, A., Brun, J. J., Jabiol, B., Ponge, J. F., and Toutain, F.: Classification of forest humus forms: a French proposal, Ann. Sci. Forest., 52, 6, 535-546, 1995.

Brown, K. A. and Bell, J. N. B.: Vegetation - the missing sink in the global cycle of carbonyl sulphide (COS), Atmos. Environ. 20, 537-540, 1986.

Campbell, J. E., Carmichael, G. R., Chai, T., Mena-Carrasco, M., Tang, Y., Blake, D. R., Blake, N. J., Vay, S. A., Collatz, G. J., Baker, I., Berry, J. A., Montzka, S. A., Sweeney, C., Schnoor, J. L., and Stanier, C. O.: Photosynthetic control of atmospheric carbonyl sulfide during the growing season, Science, 322, 10851088, doi:10.1126/science.1164015, 2008.

Campbell, J. E., Whelan, M. E., Seibt, U., Smith, S. J., Berry, J. A., and Hilton, T. W.: Atmospheric carbonyl sulfide sources from anthropogenic activity: Implications for carbon cycle constraints, Geophys. Res. Lett., 42, 3004-3010, doi:10.1002/2015GL063445, 2015.

Commane, R., Meredith, L. K., Baker, I. T., Berry, J. A., Munger, J. W., Montzka, S. A., Templer, P. H., Juice, S. M., Zahniser, M. S., and Wofsy, S. C.: Seasonal fluxes of carbonyl sulfide in a midlatitude forest, P. Natl. Acad. Sci. USA, 112, 46, 14162-14167, doi:10.1073/pnas.1504131112, 2015

Cros, B., Durand, P., Cachier, H., Drobinski, P., Fréjafon, E., Kottmeier, C., Perros, P. E., Peuch, V.-H., Ponche, J.-L., Robin, D., Saïd, F., Toupance, G., and Wortham, H.: The ESCOMPTE program: an overview, Atmos. Res., 69, 241-279, 2004

Genard-Zielinski, A.-C., Boissard, C., Fernandez, C., Kalogridis, C., Lathière, J., Gros, V., Bonnaire, N., and Ormeño, E.: Variability of BVOC emissions from a Mediterranean mixed forest in southern France with a focus on Quercus pubescens, Atmos. Chem. Phys., 15, 431-446, doi:10.5194/acp-15-431-2015, 2015.

Goldan, P. D., Fall, R., Kuster, W. C., and Fehsenfeld, F. C.: Uptake of COS by growing vegetation: a major tropospheric sink, J. Geophys. Res., 93, 14186-14192, 1988.

Hilton, T. W., Zumkehr A., Kulkarni, S., Berry, J. A., Whelan, M. E., and Campbell, J. E.: Large variability in ecosystem models explains a critical parameter for quantifying GPP with atmospheric carbonyl sulfide, Tellus B, 67, 26329, doi:10.3402/tellusb.v67.26329, 2015.

IUSS Working Group WRB: World Reference Base for Soil Resources 2014. International soil classification system for naming soils and creating legends for soil maps. World Soil Resources Reports No. 106. FAO, Rome, Italy, 2014.

Kalogridis, C., Gros, V., Sarda-Esteve, R., Langford, B., Loubet, B., Bonsang, B., Bonnaire, N., Nemitz, E., Genard, A.-C., Boissard, C., Fernandez, C., Ormeño, E., Baisnée, D., Reiter, I., and Lathière, J.: Concentrations and fluxes of isoprene and oxygenated VOCs at a French Mediterranean oak forest, Atmos. Chem. Phys., 14, 10085-10102, doi:10.5194/acp-14-10085-2014, 2014

Kalthoff, N., Kottmeier, C., Thürauf, J., Corsmeier, U., Saï, F., Fréjafon, E., and Perros, P. E.: Mesoscale circulation systems and ozone concentrations during ESCOMPTE: a case study from IOP 2b, Atmos. Res., 74, 355-380, 2005.

Kato, H., Saito, M., Nagahata, Y., and Katayama, Y.: Degradation of ambient carbonyl sulfide by Mycobacterium spp. in soil, Microbiology, 154, 249-255, doi:10.1099/mic.0.2007/011213-0, 2008. 
Kooijmans, L. M. J., Uitslag, N. A. M., Zahniser, M. S., Nelson, D. D., Montzka, S. A., and Chen, H.: Continuous and high-precision atmospheric concentration measurements of $\mathrm{COS}, \mathrm{CO}_{2}, \mathrm{CO}$ and $\mathrm{H}_{2} \mathrm{O}$ using a quantum cascade laser spectrometer (QCLS), Atmos. Meas. Tech., 9, 5293-5314, doi:10.5194/amt-9-5293-2016, 2016.

Kowalski, A. S., Loustau, D., Berbigier, P., Manca, G., Tedeschi, V., Borghetti, M., Valentini, R., Kolari, P., Berninger, F., Rannik, U., Hari, P., Rayment, M., Mencuccini, M., Moncrieff, J., and Grace, J.: Paired comparisons of carbon exchange between undisturbed and regenerating stands in four managed forests in Europe, Glob. Change Biol., 10, 1707-1723, doi:10.1111/j.13652486.2004.00846.x, 2004.

Kuai, L., Worden, J. R., Campbell, J. E., Kulawik, S. S., Li, K.-F., Lee, M., Weidner, R. J., Montzka, S. A., Moore, F. L., Berry, J. A., Baker, I., Denning, A. S., Bian, H., Bowman, K. W., Liu, J., and Yung, Y. L.: Estimate of carbonyl sulfide tropical oceanic surface fluxes using Aura Tropospheric Emission Spectrometer observations, J. Geophys. Res.-Atmos., 120, 11012-11023, doi:10.1002/2015JD023493, 2015.

Kuhn, U., Ammann, C., Wolf, A., Meixner, F. X., Andreae, M. O., and Kesselmeier, J.: Carbonyl sulfide exchange on an ecosystem scale: soil represents a dominant sink for atmospheric COS, Atmos. Environ., 33, 995-1008, 1999.

Lamaud, E., Loubet, B., Irvine, M., Stella, P., Personne, E., and Cellier, P.: Partitioning of ozone deposition over a developed maize crop between stomatal and non-stomatal uptakes, using eddycovariance flux measurements and modelling, Agr. Forest. Meteorol., 149, 1385-1396, doi:10.1016/j.agrformet.2009.03.017, 2009.

Laothawornkitkul, J., Taylor, J. E., Paul, N. D., and Hewitt, C. N.: Biogenic volatile organic compounds in the earth system, New Phytol., 183, 27-51, doi:10.1111/j.1469-8137.2009.02859.x, 2009.

Launois, T., Peylin, P., Belviso, S., and Poulter, B.: A new model of the global biogeochemical cycle of carbonyl sulfide - Part 2: Use of carbonyl sulfide to constrain gross primary productivity in current vegetation models, Atmos. Chem. Phys., 15, 9285-9312, doi:10.5194/acp-15-9285-2015, 2015.

Loubet, B., Laville, P., Lehuger, S., Larmanou, E., Fléchard, C., Mascher, N., Genermont, S., Roche, R., Ferrara, R. M., Stella, P., Personne, E., Durand, B., Decuq, C., Flura, D., Masson, S., Fanucci, O., Rampon, J.-N., Siemens, J., Kindler, R., Gabrielle, B., Schrumpf, M., and Cellier P.: Carbon, nitrogen and greenhouse gases budgets over a four years crop rotation in northern France, Plant Soil, 343, 109-137, 2011.

Maselli, F., Cherubini, P., Chiesi, M., Gilabert, M. A., Lombardi, F., Moreno, A., Teobaldelli, M., and Tognetti, R.: Start of the dry season as a main determinant of inter-annual Mediterranean forest production variations, Agr. Forest. Meteorol., 194, 197206, 2014.

Maseyk, K., Berry, J. A., Billesbach, D., Campbell, J. E., Torn, M. S., Zahniser, M., and Seibt, U.: Sources and sinks of carbonyl sulfide in an agricultural field in the Southern Great Plains, P. Natl. Acad. Sci. USA, 111, 9064-9069, doi:10.1073/pnas.1319132111, 2014.

Mihalopoulos, N., Bonsang, B., Nguyen, B. C., Kanakidou, M., and Belviso, S.: Field observations of carbonyl sulfide deficit near the ground : possible implication of vegetation, Atmos. Environ., 23 , 2159-2166, 1989.

Montzka, S. A., Calvert, P., Hall, B. D., Elkins, J. W., Conway, T. J., Tans, P. P., and Sweeney, C.: On the global distribution, seasonality, and budget of atmospheric carbonyl sulfide (COS) and some similarities to $\mathrm{CO}_{2}$, J. Geophys. Res.-Atmos., 112 , D09302, doi:10.1029/2006JD007665, 2007.

Muller, J. B. A., Percival, C. J., Gallagher, M. W., Fowler, D., Coyle, M., and Nemitz, E.: Sources of uncertainty in eddy covariance ozone flux measurements made by dry chemiluminescence fast response analysers, Atmos. Meas. Tech., 3, 163-176, doi:10.5194/amt-3-163-2010, 2010.

Ogawa, T., Noguchi, K., Saito, M., Nagahata, Y., Kato, H., Ohtaki, A., Nakayama, H., Dohmae, N., Matsushita, Y., Odaka, M., Yohda, M., Nyunoya, H., and Katayama, Y.: Carbonyl sulfide hydrolase from Thiobacillus thioparus strain THI115 is one of the $\beta$ carbonic anhydrase family enzymes, J. Am. Chem. Soc., 135, 3818-3825, doi:10.1021/ja307735e, 2013.

Ogée, J., Sauze, J., Kesselmeier, J., Genty, B., Van Diest, H., Launois, T., and Wingate, L.: A new mechanistic framework to predict OCS fluxes from soils, Biogeosciences, 13, 2221-2240, doi:10.5194/bg-13-2221-2016, 2016.

Santonja, M., Fernandez, C., Gauquelin, T., and Baldy, B.: Climate change effects on litter decomposition: intensive drought leads to a strong decrease of litter mixture interactions, Plant Soil, 393, 69-82, 2015.

Seibt, U., Kesselmeier, J., Sandoval-Soto, L., Kuhn, U., and Berry, J. A.: A kinetic analysis of leaf uptake of COS and its relation to transpiration, photosynthesis and carbon isotope fractionation, Biogeosciences, 7, 333-341, doi:10.5194/bg-7-333-2010, 2010.

Stein, A. F., Draxler, R. R., Rolph, G. D., Stunder, B. J. B., Cohen, M. D., and Ngan, F.: NOAA's HYSPLIT atmospheric transport and dispersion modeling system, B. Am. Meteorol. Soc., 96, 2059-2077, doi:10.1175/BAMS-D-14-00110.1, 2015.

Stella, P., Loubet, B., Lamaud, E., Laville, P., and Cellier, P.: Ozone deposition onto bare soil: a new parameterisation, Agr. Forest. Meteorol., 151, 669-681, 2011.

Stimler, K., Montzka, S. A., Berry, J. A., Rudich, Y., and Yakir, D.: Relationships between carbonyl sulfide (COS) and $\mathrm{CO}_{2}$ during leaf gas exchange, New Phytol., 186, 869-878, 2010.

Stimler, K., Berry, J. A., Montzka, S. A., and Yakir, D.: Association between carbonyl sulfide uptake and ${ }^{18} \Delta$ during gas exchange in $\mathrm{C}_{3}$ and $\mathrm{C}_{4}$ Leaves, Plant Physiol., 157, 509-517, 2011.

Sun, W., Maseyk, K., Lett, C., and Seibt, U.: A soil diffusionreaction model for surface COS flux: COSSM v1, Geosci. Model Dev., 8, 3055-3070, doi:10.5194/gmd-8-3055-2015, 2015.

Van Diest, H. and Kesselmeier, J.: Soil atmosphere exchange of carbonyl sulfide (COS) regulated by diffusivity depending on waterfilled pore space, Biogeosciences, 5, 475-483, doi:10.5194/bg-5475-2008, 2008.

Whelan, M. E., Hilton, T. W., Berry, J. A., Berkelhammer, M., Desai, A. R., and Campbell, J. E.: Carbonyl sulfide exchange in soils for better estimates of ecosystem carbon uptake, Atmos. Chem. Phys., 16, 3711-3726, doi:10.5194/acp-16-3711-2016, 2016.

White, M. L., Zhou, Y., Russo, R. S., Mao, H., Talbot, R., Varner, R. K., and Sive, B. C.: Carbonyl sulfide exchange in a temperate loblolly pine forest grown under ambient and elevated $\mathrm{CO}_{2}$, Atmos. Chem. Phys., 10, 547-561, doi:10.5194/acp-10-547-2010, 2010. 
Wingate, L., Seibt, U., Maseyk, K., Ogée, J., Almeida, P., Yakir, D., Pereira, J. S., and Mencuccini, M.: Evaporation and carbonic anhydrase activity recorded in oxygen isotope signatures of net $\mathrm{CO}_{2}$ fluxes from a Mediterranean soil, Glob. Change Biol., 14, 2178-2193, doi:10.1111/j.1365-2486.2008.01635.x, 2008.

Wohlfahrt, G., Brilli, F., Hörtnagl, L., Xu, X., Bingemer, H., Hansel, A., and Loreto, F.: Carbonyl sulfide (COS) as a tracer for canopy photosynthesis, transpiration and stomatal conductance: potential and limitations, Plant Cell Environ., 35, 657-667, 2012.
Yver Kwok, C., Laurent, O., Guemri, A., Philippon, C., Wastine, B., Rella, C. W., Vuillemin, C., Truong, F., Delmotte, M., Kazan, V., Darding, M., Lebègue, B., Kaiser, C., Xueref-Rémy, I., and Ramonet, M.: Comprehensive laboratory and field testing of cavity ring-down spectroscopy analyzers measuring $\mathrm{H}_{2} \mathrm{O}, \mathrm{CO}_{2}, \mathrm{CH}_{4}$ and CO, Atmos. Meas. Tech., 8, 3867-3892, doi:10.5194/amt-83867-2015, 2015. 